\title{
Delusions and Violent Behavior: A Short Review of the Recent Literature
}

\author{
Nystazaki Maria, Papadimitriou Maria, Nikolaou Nikolaos and Alevizopoulos Giorgos* \\ Psychiatric Clinic, Agioi Anargyroi Hospital, National and Kapodistrian University o Athens, Greece \\ Submission: April 04, 2017; Published: May 24, 2017
}

*Corresponding author: Alevizopoulos Giorgos, Psychiatric Clinic, Agioi Anargyroi Hospital, National and Kapodistrian University o Athens, Greece, Tel: 2103501567; Email: giorgosalevizopoulos@gmail.com

\section{Editorial}

\section{Introduction}

The literature supports an agreement that rates of violence are higher in people with a diagnosis of schizophrenia compared with the general population [1] and the above can be explained by the fact that individuals with serious mental illnesses such as schizophrenia, are over presented in the criminal justice system [2-4]. It is generally believed that the reason for the high prevalence rates of people with mental illness in prison is due to the fact that the prevalence of aggressive and violent acts are rather higher among people with mental illness [5,6]. To add to the above perception, the general public regards those with mental illness, as a group of people dangerous and violent, who worth to be avoided increasing the stigma and marginalization of the mentally ill [5].

There is an ongoing debate, on whether violence can be driven by symptoms of psychosis per se or not. Earlier studies suggest that violence can be associated with psychotic symptoms $[7,8]$, and rates of violence are higher in people with a diagnosis of schizophrenia compared to the general population [1]. In addition to the above findings reanalysis of data from the National Epidemiologic Survey of Alcohol and Related Conditions (NESARC) revealed a statistically significant, yet modest relationship between major mental illness and violence [9]. Nevertheless, not every study has confirmed a higher risk of violence linked with the presence of psychosis or severe mental illness and a number of studies have shown that the key risk factors for violence are the same among psychotic patients and the general population $[10,11]$.

Data from the MacArthur Violence Risk Assessment study showed that psychotic patients, recently discharged from the hospital, without alcohol or drug symptoms, were not significantly more violent than comparison group subjects without alcohol or drug symptoms (4.7 vs. 3.3\%) [12]. A recent analysis of 1000 psychiatric patients with repeated incidents of violence over a year (part of the MacArthurViolence Study) showed that psychosis preceded violence for $12 \%$ of violent incidents [13]. Since, the vast majority of the forensic literature supports an association between violence and severe mental illness, a number of studies $[14,15]$ aimed to the identification of specific factors, such as psychotic symptoms, such as delusions and hallucinations, [16,17] substance misuse, personality traits etc. [18] that could be associated with violent behavior in persons with mental illness. Among the various risk factors, delusional thinking seems to be an important candidate that precipitates violence among people with psychotic disorders [17]. Persecutory delusions, delusions of control and delusions of reference, in which patients believe that people are seeking to harm them, talking in a negative way about them or that outside forces are controlling their minds, are amongst the core positive symptoms of schizophrenia [19] and are considered by many to be important causative factors for violent behavior [17].

Systematic studies from forensic and civil patient populations have confirmed that even though most violence perpetrated by psychotic persons is not motivated by delusional thinking $[12,20,21]$, a substantial minority of their violent acts appears to stem from the type and content of the delusions. Delusions involving the possibility of a threat to the physical integrity have been implicated in the onset of violent behavior in psychotic patients. Thus schizophrenic individuals often incited by these delusions react violently in response to a real or imagined threat. Then the possible sense of threat acts as a catalyst in the event of violent behavior inspired by the delusional construction [21].

Earlier studies have suggested that delusional symptoms such as threat/control-override will lead to violence if they cause a person to perceive others as harmful (e.g. threat delusions) or when these symptoms intrude in such a way as to override internal controls (e.g. influence delusions) [22,23]. However, 
other studies have found that especially threat delusions (not control-override delusions) are also associated with violent behavior [24,25].

Findings from the Clinical Antipsychotic Trial of Intervention Effectiveness (CATIE) study, a naturalistic multicentre trial, showed that hallucinations accompanied by delusional interpretations, and delusional thinking associated with suspiciousness and feelings of persecution, were related to serious violence among patients with schizophrenia, more specifically among the 7 symptom ratings that compose the PANSS positive subscale, 5 specific symptoms (hostility, suspiciousness/persecution, hallucinatory behavior, grandiosity and excitement) were significantly associated with increased risk of serious violence among schizophrenia patients living in the community [26].

People with persecutory delusions have the conviction that others will cause them harm, currently or in the future [27], and that the harm will be intentional. Freeman and colleagues (2007) proposed that people with such experiences use safety behaviors, such as avoidance or aggression, to reduce the threat that they perceive [28]. Although avoidance behaviors appeared to be the most common of these, and aggression one of the least likely, there is a positive and significant association between persecutory delusions and aggression. A possible link in this relationship may be the presence of delusion-related distress [24].

Furthermore, it has been suggested that patients who have acted in any way violently were more likely to report that delusions made them angry. A study by Coid and colleagues based on an epidemiological survey of first episode psychosis, during a 2-year period, found a strong association between anger due to delusions and serious violence. A small number of uncommon delusional beliefs demonstrated direct pathways leading to minor violence. Three highly prevalent delusions demonstrated pathways to serious violence mediated by anger due to delusional beliefs: persecution, being spied on and conspiracy [17]. In a longitudinal community study of 1136 male and female psychiatric patients after discharge, delusions, affect due to delusions, and violence indicated association between specific delusions (being spied upon, being followed, being plotted against and having special gifts/powers with angry effect), supporting an indirect pathway towards violence and delusions [29].

It appears that angry affect is an important component in a causal model of mental illness and violence [30]. It is reasonable to hypothesize that frequent beliefs that others intend harm may contribute to the use of aggressive behavior to remove a perceived threat [24]. In a systematic review conducted by Darrell-Berry and colleagues examining paranoia and its relationship with aggression in the context of schizophrenia, a link between aggression and general paranoid delusions and specific threat to self-delusions was reported [31] findings consistent with previous literature [32,33]. Interestingly, the above studies all come to the agreement that anger due to delusions leads to violent acts. Reactive aggression is considered the ultimate behavioral expression of anger in response to a threat and delusions of persecution, conspiracy, and being spied on, leading to serious violence [34], could constitute extreme threat to a psychotic patient [35].

In addition paranoid individuals may utilise aggression as safety behaviour in an effort to maintain their 'safety' and/or prevent threats [28]. Despite the fact that various studies are all consistent in finding that symptoms of mental illness only cause crime in a minority of cases (between $4 \%$ and $12 \%$ ) the fact is that there is constant and robust evidence of an association between delusions and violence acts [26]. Perhaps the most important finding arising from this short review is that anger due to delusional thinking is a key factor that explains the relationship between violence and psychosis.

\section{Acknowledgement}

We would like to thank Gkartzoni Vasiliki for her substantial support in reviewing the literature. This paper supported partially by an educational grant provided by Y.P.O.LEI.PSY.

\section{References}

1. Fazel S, Wolf A, Palm C, Lichtenstein P (2014) Violent crime, suicide, and premature mortality in patients with schizophrenia and related disorders: a 38-year total population study in Sweden. Lancet Psychiatry 1(1): 44-54.

2. Fazel S, Danesh J (2002) Serious Mental Disorder in 23,000 Prisoners: A Systematic Review of 62 Surveys. Lancet Psychiatry 359: 545-548.

3. Steadman HJ, Osher FC, Robbins P, Case B, Samuels S (2009) Prevalence of serious mental illness among jail inmates. Psychiatric Servs 60(6): 761-765.

4. Igoumenou A, Alevizopoulos GA (2016) Psychiatric disorders and criminal history in male prisoners in Greece. Int J Law Psychiatry 47: 171-175.

5. Van Dorn RA, Swanson JW, Elbogen EB, Swartz MS (2005) A comparison of stigmatizing attitudes toward persons with schizophrenia in four stakeholder groups: perceived likelihood of violence and desire for social distance. Psychiatry 68(2): 152- 163.

6. Link BG, Stueve A, Phelan J (1998) Psychotic symptoms and violent behaviors: probing the components of "threat/control-override" symptoms. Soc Psychiatry Psychiatr Epidemiol 33: S55-S60.

7. McNiel DE, Eisner JP, Binder RL (2000) The relationship between command hallucinations and violence. Psychiatr Serv 51(10): 12881292.

8. Fox JRE, Gray NS, Lewis H (2004) Factors determining compliance with command hallucinations with violent content: the role of social rank, perceived power of the voice and voice malevolence. J Forensic Psychiatry Psychol 15(3): 511-531.

9. Van Dorn R, Volavka J, Johnson N (2012) Mental disorder and violence: is there a relationship beyond substance use? Soc Psychiatry Psychiatr Epidemiol 47:487-503.

10. Coid J, Yang M, Roberts A, Ullrich S, Moran P, et al. (2006) Violence and 
psychiatric morbidity in a national household population-a report from the British Household Survey. Am J Epidemiol 164: 1199-1208.

11. Elbogen EB, Johnson SC (2009) The intricate link between violence and mental disorder: results from the National Epidemiologic Survey on Alcohol and Related Conditions. Arch Gen Psychiatry 66(2): 152161.

12. Appelbaum PS, Robbins PC, Monahan J (2000) Violence and delusions: data from the MacArthur Violence Risk Assessment Study. Am J Psychiatry 157(2): 566-572.

13. Skeem J, Kennealy P, Monahan J, Peterson J, Appelbaum P (2015) Psychosis uncommonly and inconsistently precedes violence among high risk individuals. Clin Psych Sci 4(1):1-10.

14. Monahan J (1992) Mental disorder and violent behavior: perceptionsand evidence. Am Psychol 47: 511-521.

15. Swanson JW, Holzer CE, Ganju VK, Jono RT (1990) Violence and psychiatric disorder in the community: evidence from the Epidemiologic Catchment Area surveys. Hosp Community Psychiatry 41:761- 770 .

16. Link BG, Andrews H, Cullen FT (1992) The violent and illegal behavior of mental patients reconsidered. Am Sociol Rev 57: 275-292.

17. Coid JW, Ullrich S, Kallis C, Keers R, Barker D, et al. (2013) The relationship between delusions and violence: findings from the East London first episode psychosis study. JAMA psychiatry 70: 465-471.

18. Mulvey EP (1994) Assessing the evidence of a link between mental illness and violence. Hosp Community Psychiatry 45: 663-668.

19. Lieberman JA, Saffermna AZ, Pollack S, Szymanski S, Johns C, et al. (1994) Clinical effects of clozapine in chronic schizophrenia: response to treatment and predictors of outcome. Am J Psychiatry 151: 17441752.

20. Junginger, J, Parks-Levy J, McGuire L (1998) Delusions and symptomconsistent violence. Psychiatr Serv 49: 218-220.

21. Junginger J, McGuire L (2004) Psychotic motivation and the paradox of current research on serious mental illness and rates of violence. Schizophr Bull 30(1): 21-30.

22. WalshE, Gilvarry C, Samele C, Harvey K, Manley C, et al. (2004) Predicting violence in schizophrenia: a prospective study. Schizophr Res 67: 247-252.

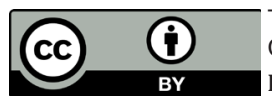

This work is licensed under Creative Commons Attribution 4.0 License

DOI: $10.19080 /$ JFSCI.2017.03.555613
23. Teasdale B, Silver E, Monahan J (2006) Gender, threat/control-override delusions and violence. Law Hum Behav 30(6): 649-658.

24. Bjørkly, S (2002) Psychotic symptoms and violence toward others - a literature review of some preliminary findings: part 1. Delusions. Aggress Violent Beh 7:617-631.

25. Stompe T, Ortwein-Swoboda G, Schanda, H (2004) Schizophrenia, delusional symptoms, and violence: the threat/control-override concept reexamined. Schizophr Bull 30: 31.

26. Swanson JW, Swartz MS, Van Dorn RA, Elbogen EB, Wagner HR, et al. (2006) A national study of violent behavior in persons with schizophrenia. Arch Gen Psychiatry 63: 490-499.

27. Freeman D, Garety, PA (2000) Comments on the content of persecutory delusions: does the definition need clarification? Br J Clin Psychol 39: 407-414.

28. Freeman D, Garety PA, Kuipers E, Fowler D, Bebbington PE, et al. (2007) Acting on persecutory delusions: the importance of safety seeking. Behav Res Ther 45(1): 89-99.

29. Ullrich S, Keers R, Coid JW (2014) Delusions, anger, and serious violence: New findings from the MacArthur violence risk assessment study. Schizophr Bull 40(5): 1174-1181.

30. Hiday VA (1995) The social context of mental illness and violence. J Health Soc Behav 36(2): 122-137.

31. Darrell-Berry H, Berry K, Bucci S (2016) The relationship between paranoia and aggression in psychosis: A systematic review. Schizophr Res 172(1): 169-176.

32. Humphreys MS, Johnstone EC, MacMillan JF, Taylor PJ (1992) Dangerous behaviour preceding first admissions for schizophrenia. British J Psychiat 161: 501-505.

33. Junginger J, Parks-Levy J, McGuire L (1998) Delusions and symptomconsistent violence. Psychiatr Serv 49: 218-220.

34. Blair R (2012) Local level violence, Yale University Press, USA.

35. Panskepp J (1998) Affective Neuroscience: The Foundations of Human and Animal Emotions. Oxford University Press, New York, NY, USA.

\section{Your next submission with Juniper Publishers will reach you the below assets}

- Quality Editorial service

- Swift Peer Review

- Reprints availability

- E-prints Service

- Manuscript Podcast for convenient understanding

- Global attainment for your research

- Manuscript accessibility in different formats

( Pdf, E-pub, Full Text, Audio)

- Unceasing customer service

Track the below URL for one-step submission

https://juniperpublishers.com/online-submission. 